\title{
Research progress of monitoring technology of ship-source air pollutants in china emission control area
}

\author{
Mao Tianyu ${ }^{1}$, Li Yajuan ${ }^{1, *}$, and Chang Fang ${ }^{1}$ \\ ${ }^{1}$ Laboratory of Waterway Environmental Protection Technology, Tianjin Water Transport Engineering Science Research Institute, \\ Tianjin 300456, China
}

\begin{abstract}
I After the implementation of ship emissions control area, the urgent need for the practical monitoring technology. This paper comprehensively studies the international and domestic cases of ship emission control monitoring: The following methods are used: direct collection of fuel oil samples for analysis, collection of ship exhaust samples and analysis, remote sensing observation of ship exhaust and analysis, as well as the use of fixed-point monitoring station system to monitor air quality. X-ray fluorescence spectroscopy is used to analyze the fuel sulfur content directly, and the carbon balance method can be used to calculate the fuel oil content,. The fixed position monitoring system is a comprehensive monitoring method, which can effectively observe the influence of the emission of the ship exhaust on air quality, and evaluate the effect of the control area. Afterwards, the application should also be concerned about the effects of various methods of comparison, alternative measures and focus on the effect of tail gas treatment facilities assessment, enhanced port area environmental monitoring networks.
\end{abstract}

\section{INTRODUCTION}

In 2008, the International Maritime Organization and its Marine Environmental Protection Committee adopted the Maritime Anti-pollution Convention (MARPOL) Annex VI in the form of a resolution, which stipulates the sulphur content standard of ship fuel and the time node for mandatory implementation [1]. On August 29, 2015, the "Air Pollution Prevention and Control Law of the People's Republic of China" was revised and passed, and it was formally implemented on January 1, 2016. Among them, the content of Article 64 is: "The competent department of transportation under the State Council may delineate air pollutant emission control areas for ships in coastal waters, and ships entering the emission control areas shall comply with relevant ship emission requirements." For the first time, it provided a legal basis for the delimitation of emission control zones. In this context, the Ministry of Transport issued the "Implementation Plan for Ship Emission Control Zones in the Pearl River Delta, Yangtze River Delta, and the Bohai Sea (Beijing-Tianjin-Hebei) Waters", which will be implemented on January 1, 2016. According to the requirements of the "Plan", In the Pearl River Delta, the Yangtze River Delta, and the Bohai Rim (BeijingTianjin-Hebei) waters, three ship air pollutant emission control zones have been established to control the sulfur content in ship fuel oil to reduce pollution represented by sulfur oxides and particulate matter To improve the environmental air quality of China's coastal and riverside areas, especially port cities, to promote energy- saving and emission reduction of ships and the development of green shipping.

Establish a ship emission control area, and the main objects of supervision are ships entering the emission control area. According to the requirements of the Plan issued at the same time, ships entering the control zone should use fuel oil with a sulfur content of less than $0.5 \%$.

\section{OVERVIEW OF OBSERVATION METHODS}

To monitor and manage the sulfur content of marine fuel oil, common observation methods include direct fuel oil sample analysis, ship exhaust sampling methods, remote sensing monitoring and analysis of ship exhaust methods, and air quality monitoring at designated monitoring stations. Moldanová, J et al. ${ }^{[2]}$ used fuel oil sampling and analysis methods in the European Emission Control Area, Daniel AL et al. ${ }^{[3]}$ used aircraft platforms in the US Emission Control Area to sample and analyze ship exhaust plumes, Berg, N., etc. ${ }^{[4]}$ Using aircraft platforms and DOAS equipment to observe the gaseous pollutants emitted by ships, L. Pirjola et al. ${ }^{[5]}$ set up fixed observation stations in Finnish ports and combined with meteorological observations to observe and analyze the environmental impact of ship exhaust gas.

\footnotetext{
* Corresponding author: 457536425@qq.com
} 


\subsection{Direct sampling analysis of marine fuel oil}

It mainly includes the following steps: first select the sample ship, then board the ship to check the ship's fuel oil records and sampling, and finally send the sample to the laboratory for analysis. This method must board the ship, obtain the test sample by directly extracting the fuel oil in use on the ship, and further conduct laboratory analysis on the sample to obtain the sulfur content of the marine fuel oil. The research process of sampling analysis is mainly laboratory analysis. The technical methods for analyzing the sulfur content of oil products in the laboratory include lamp sulfur method (GB/T38088), tube sulfur method (GB/T387-90) ${ }^{[6]}$ and X-ray fluorescence spectrometry. The general methods are all It is necessary to react the sample with oxygen or hydrogen to generate $\mathrm{SO}_{2}$ or hydrogen sulfide, and then indirectly calculate the total sulfur content by detecting the content of $\mathrm{SO}_{2}$ or hydrogen sulfide. Therefore, X-ray fluorescence spectrometry (XRF) has gradually been widely used because of its convenience, no need to burn samples, and accurate results. It can be applied to the latest version of the standard "Determination of Sulfur Content in Petroleum and Petroleum Products. Energy Dispersion" X-ray fluorescence spectrometry (GB/T 17040-2008)".

X-ray fluorescence spectroscopy (XRF) utilizes the phenomenon that secondary X-rays (fluorescence) are generated after high-energy X-rays irradiate the test substance. The amount of fluorescence corresponds to the content of sulfur atoms in the sample, and the sulfur content in the sample can be calculated by detecting the amount of fluorescence. The detection limit of sulfur in petroleum products is $0.6 \mathrm{mg} / \mathrm{kg}$, and the accuracy can meet emission control. District management requirements.

The United States once published the Standard ASTM-D 7039 (latest version was revised in 2004), which stipulates the use of XRF method to observe the sulfur content of petroleum products. In China, the current standard "Determination of Sulfur Content in Petroleum and Petroleum Products Energy Dispersive Xray Fluorescence Spectrometry (GB/T 17040-2008)" also adopts this method. In recent years, many different types of equipment using XRF principles have been developed and produced. Suitable XRF instruments and equipment are used for different analytical purposes. Small portable XRF equipment can be selected for onsite rapid initial inspection, or through necessary sample processing in the laboratory. Analysis of large-scale XRF equipment ${ }^{[17]}$. XRF equipment is widely used in the detection of domestic petroleum products, and can also observe the content of other elements with high accuracy. ${ }^{[6]}$

\subsection{Ship tail gas sampling and analysis method}

Use various platforms or boarding methods to directly obtain ship exhaust samples. Through the analysis and detection of exhaust gas samples, the sulfur oxide content and carbon dioxide content are obtained, and the sulfur content of marine fuel is further analyzed according to the fuel carbon balance algorithm. To observe the $\mathrm{CO}_{2}$ content and $\mathrm{SO}_{2}$ content in the exhaust gas, the NDIR method is commonly used. This method can also analyze other pollutant gas components such as $\mathrm{NOx}$ and $\mathrm{CO}$ in the exhaust plume.

The basic principle of the fuel carbon balance algorithm is that the composition of atoms will not change before and after the fuel is burned. The proportion of carbon and sulfur in the corresponding fuel should also be the same in the exhaust gas. Finnish scholars such as L. Pirjola derived the formula for calculating the sulfur content based on carbon balance as:

$$
\mathrm{FSC} \approx \frac{\Delta \mathrm{SO}_{2}}{\Delta \mathrm{CO}_{2}} \cdot 0.23
$$

Where: FSC refers to the sulfur content of fuel oil, in $\% ; \Delta \mathrm{SO}_{2}$ represents the concentration of $\mathrm{SO}_{2}$ in ship exhaust, in ppb; $\Delta \mathrm{CO}_{2}$ represents the concentration of $\mathrm{CO}_{2}$ in ship exhaust, in ppm. ${ }^{[5]}$ It is also mentioned that about $6 \%$ to $0.7 \%$ of the sulfur in the fuel may be converted into $\mathrm{SO}_{3}$.

The basic principle of non-dispersive infrared spectrophotometry (NDIR method) is Beer-Lambert law (Beer-Lambert law), which is the basic law of light absorption, applicable to all electromagnetic radiation and all light-absorbing substances, including gas, solid, liquid, Molecules, atoms and ions. This method has high accuracy, the detection limit can reach ppm level, the response is fast, no complicated test equipment is needed, and data can be quickly observed on site. This method is also used to observe $\mathrm{SO}_{2}$ in the observation of ship exhaust in the European Emission Control Area ${ }^{[2]}$.

The detection of $\mathrm{SO}_{2}$ generally uses ultraviolet fluorescent (ultra-violet fluorescent) method, with mature monitoring equipment, which can be used on mobile vehicle platforms with an accuracy of ppb. It has been used in the observation of $\mathrm{SO}_{2}$ emissions from ships exhaust in the ports of Turku and Helsinki in Finland ${ }^{[5]}$.

\subsection{The method of monitoring air quality by the port designated monitoring station system}

This method requires the establishment of a certain scale of port air monitoring station network, comprehensive observation of air quality in the port area, combined with pollution source emission inventory, meteorological and geographic data and air pollution diffusion model analysis, and then discover and locate suspected ships, and focus on sampling survey.

\section{VERIFICATION EXPERIMENT}

In order to explore whether formula (1) can be applied locally and to further understand the degree of influence of environmental conditions on this kind of observation process, a formal observation is set up as a verification experiment. 


\subsection{Observation scenarios:}

In October 2016, we chose to set up a measuring point in the open area within 500 meters of the main waterway of a northern port. The measuring points are continuously observed for many days, the $\mathrm{SO} 2$ and $\mathrm{CO} 2$ of ship exhaust gas are observed, and the meteorological conditions are observed at the same time. On-site observations were recorded as follows:

Table 1 Record of observation days of main channel of a port

\begin{tabular}{|c|c|c|c|c|}
\hline & Date & $\begin{array}{c}\text { Samplin } \\
\text { g period }\end{array}$ & $\begin{array}{c}\text { Effective } \\
\text { period }\end{array}$ & $\begin{array}{c}\text { main wind } \\
\text { direction }\end{array}$ \\
\hline 1 & $2016 / 10 / 24$ & $\begin{array}{c}09: 00- \\
17: 00\end{array}$ & $\begin{array}{c}09: 30- \\
17: 00\end{array}$ & Static wind \\
\hline 2 & $2016 / 10 / 25$ & $\begin{array}{c}09: 00- \\
17: 20\end{array}$ & $\begin{array}{c}15: 30- \\
17: 20\end{array}$ & $\mathrm{~S}$ \\
\hline 3 & $2016 / 10 / 26$ & $\begin{array}{c}09: 00- \\
17: 00\end{array}$ & $\begin{array}{c}10: 00- \\
17: 00\end{array}$ & $\mathrm{NE}$ \\
\hline 4 & $2016 / 10 / 31$ & $\begin{array}{c}09: 00- \\
17: 17\end{array}$ & $\begin{array}{c}09: 30- \\
17: 00\end{array}$ & NEN \\
\hline 5 & $2016 / 11 / 01$ & $\begin{array}{c}09: 16- \\
16: 50\end{array}$ & $\begin{array}{c}09: 30- \\
16: 49\end{array}$ & $\begin{array}{c}\text { N } \\
\text { (Morning) } \\
\text { SWS }\end{array}$ \\
\hline
\end{tabular}

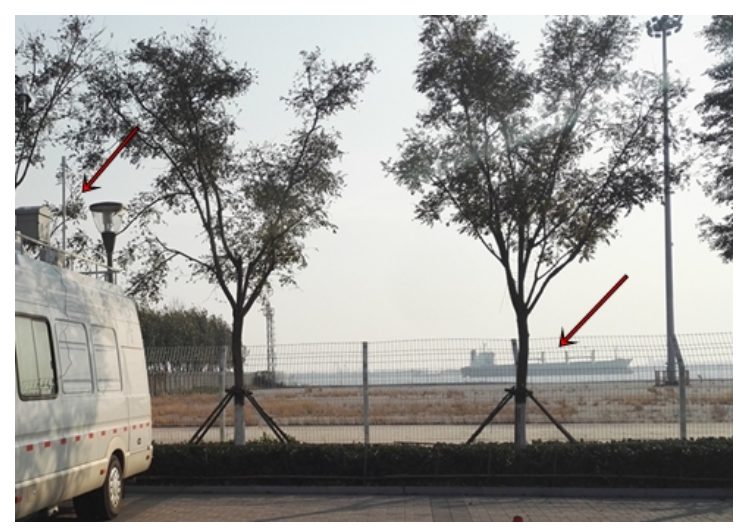

Figure 1 observation site photo 20161101-15:06(left arrow refers to instrument sampling port, right arrow refers to cargo ship)

Table 2 Performance of instruments used for observation

\begin{tabular}{|l|l|l|}
\hline Indicators & Instruments & Performance \\
\hline SO2 & $\begin{array}{l}\text { ECOTECH } \\
9850\end{array}$ & $\begin{array}{l}\text { Range 0-20 ppm, Noise } \\
0.2 \mathrm{ppb} \text {, Minimum } \\
\text { detection limit 0.4 ppb, } \\
\text { Response time T95<100 }\end{array}$ \\
\hline & $\begin{array}{l}\text { Range 0-200 ppm, Noise } \\
0.02 \text { ppm, Minimum } \\
\text { detection limit 40 ppb, } \\
\text { Response time T95<40 }\end{array}$ \\
\hline \multirow{2}{CO}{2} & $\begin{array}{l}\text { ECOTECH } \\
\text { alectrochemic } \\
\text { Connector, } \\
\text { UK }\end{array}$ & Foreword \\
\hline
\end{tabular}

\subsection{Observation process and analysis of results}

After all instruments are stabilized, record a set of data per minute. The data are arranged according to time series, each pollutant unit is ppb,CO2 unit is ppm, and the pollutant concentration is distributed according to time. Find SO2 peak data from it. Then put into the previous formula (1) for trial calculation. The time series of pollutants is shown in figure 2. As seen in the figure SO2 there are several obvious peaks. In particular, the peak around 15:00 is very obvious, and in figure 1, we can see that there is a ship passing by.



Figure 2 Time series diagram of pollutant concentration

Therefore, the data of 20 minutes before and after 15:00 are put forward to further analyze their relationship. Figure 3 can be given.

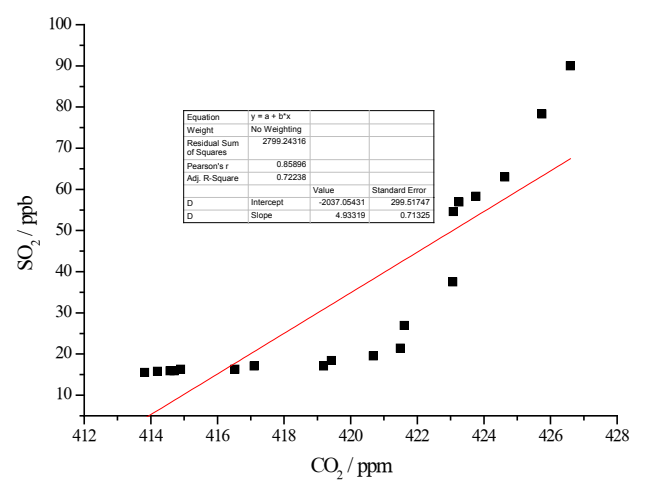

Figure 3 SO2 Relationship Analysis with CO2 Data

According to the calculation of formula (1), the results of relevant data are substituted into the formula: according to

$$
\begin{aligned}
\mathrm{FSC}(\%) & =\Delta \mathrm{SO}_{2}(\mathrm{ppb}) \times 10^{-3} / \Delta \mathrm{CO}_{2}(\mathrm{ppm}) \times \mathrm{M}_{\mathrm{s}} / \mathrm{MCO}_{\mathrm{C}} \times 100 \\
& \approx \Delta \mathrm{SO}_{2}(\mathrm{ppb}) / \Delta \mathrm{CO}_{2}(\mathrm{ppm}) \times 0.23 \\
& \approx(4.93319 \pm 0.71325) \times 0.23 \\
& =1.13 \pm 0.16
\end{aligned}
$$

As a result, it can be deduced that the sulphur content of the oil used by vessels appearing at 3 points in the region is $1.13 \pm 0.16$ percent.

This data is consistent with the general scenario of the sulfur content of local marine diesel at that time.

This method is feasible to judge the sulfur content of marine diesel oil under suitable environmental conditions. 


\section{DISCUSSION}

4.1 The analysis technology is basically mature, but it lacks practical sampling methods and cannot meet the regulatory requirements.

Through the verification experiment and the result calculation, it can be seen that the method of observing the $\mathrm{SO} 2$ and $\mathrm{CO} 2$ concentration in the waste gas of the ship and further calculating the sulfur content of the fuel oil is of application value. $\mathrm{CO} 2$ and sulphur oxides for ship-emitting gases can also be prioritized for monitoring in areas where there are fewer sources of pollution and relatively low ship flows. The sulfur content of ship fuel oil can be calculated by using the carbon balance algorithm in tail gas monitoring method. The application conditions and accuracy of this method should be further explored. Whether it is the sulfur content in ship fuel oil samples or the $\mathrm{SO}_{2}$ content in ship tail gas, there are mature methods that can meet the analysis requirements. However, because of the ship's own moving characteristics, it is more difficult to directly obtain accurate fuel samples. However, due to special requirements such as aviation control and safe operation, there is no method that can fully meet the regulatory requirements for the time being. In the future, it is necessary to develop an observation platform system that adapts to all kinds of weather, quickly obtains reliable data, is relatively automated, and is easy to deploy.

\subsection{Strengthen the monitoring force of the port area}

The port environmental monitoring station plays an irreplaceable role in supervising the oil consumption of ships and evaluating the effect of reducing emissions in the port area. The foregoing introduction shows that neither fuel oil sampling nor exhaust gas sampling can reflect the degree of improvement in ambient air quality. Assessing the implementation effects of control measures in emission control areas requires continuous observation of air quality throughout the port area. According to the requirements of the "plan", to carry out the evaluation of the implementation effect at the end of 2019 , there is an urgent need for a series of air quality change data in the port area over a longer period of time. To obtain these observation data, the construction of the port environmental monitoring station network should be carried out as soon as possible.

\section{ACKNOWLEDGMENTS}

This paper is one of the phased achievements of "Special Fund Project of Fundamental Scientific Research Business Expenses of Tianjin Institute of Water Transportation Engineering Research, Ministry of Transport (TKS160209, TKS160210)".

\section{REFERENCES}

1. Annex, V. I. (1998). "of MARPOL 73/78, Regulations for the prevention of air pollution from ships and NOx technical code." IMO London.

2. Moldanová, J., Fridell, E. , Winnes, H. , HolminFridell, S. , Boman, J. , \& Jedynska, A., et al. (2013). Physical and chemical characterisation of pm emissions from two ships operating in european emission control areas. Atmospheric Measurement Techniques, 6(2), 3931-3982.

3. Lack D A, Cappa C D, Langridge J, et al. (2011). Impact of fuel quality regulation and speed reductions on shipping emissions: implications for climate and air quality. Environmental Science \& Technology, 45(20), 9052-9060.

4. Berg, N. and J. Mellqvist, et al. (2012). "Ship emissions of SO2 and NO2: DOAS measurements from airborne platforms." Atmospheric Measurement Techniques 5 (5): 6273-6313.

5. Pirjola, L. and A. Pajunoja, et al. (2014). "Mobile measurements of ship emissions in two harbour areas in Finland." Atmospheric Measurement Techniques 7 (1): 149-161.

6. Luo Jianlin. (2003). Application of Energy Dispersive X-ray Fluorescence Spectrometry in the Determination of Sulfur Content in Oils[J]. Analytical Instruments, 3(03):31-34. 